http://jmscr.igmpublication.org/home/ ISSN (e)-2347-176x ISSN (p) 2455-0450 crossref DOI: https://dx.doi.org/10.18535/jmscr/v9i1.50

Journal Of Medical Science And Clinical Research

\title{
Comparative Study of Endometrial Aspiration Cytology Using Pipelle with Hysteroscopic Guided Endometrial Biopsy in Patient with AUB (Abnormal Uterine Bleeding)
}

Authors

\section{Dr Shivangi, Prof Dr Tapasi Pati, Prof Dr Debahuti Mohapatra}

\begin{abstract}
Abnormal uterine bleeding is one of the most common problems in perimenopausal age group. The proportion is $9-30 \%$ in reproductive age group. This proportion rises to $70 \%$ in perimenopausal and postmenopausal women. Abnormal uterine bleeding (AUB) warrants a thorough evaluation in perimenopausal women and hence it's important to perform it in a cost-effective manner with available resources.

Aims and Objectives: Compare the efficacy of endometrial cytology with hysteroscopy guided biopsy.

Inclusion Criteria: women above 35 years of age with symptoms suggestive of AUB.

Exclusion Criteria: Pregnant patient and patient with genital tract infection, coagulation disorder and genital malignancy.

Conclusion: Endometrial sampling using Pipelle is an easy and safe method. It has high sensitivity, specificity, positive and negative predictive values when compared to hysteroscopy. Thus, to obtain adequate endometrial sample, Pipelle biopsy should be considered as primary investigation.

Keywords: Abnormal uterine bleeding, FIGO, PALM-COEIN.
\end{abstract}

\section{Introduction}

A significant proportion of the surgical workload of a gynaecological department involves the exclusion endometrial pathology in middle aged and older women, who present with abnormal uterine bleeding. Abnormal uterine bleeding is most common problems in the perimenopausal age group. Abnormal uterine bleeding (AUB) includes any disturbance in the frequency, regularity, duration or volume of menstrual flow, and non-menstrual disturbance of any cause. ${ }^{[1]}$ Abnormal uterine bleeding is one of the most frequent problem encountered in the life of women. One third of total women attending gynaecology OPD presents with complaints of abnormal uterine bleeding. ${ }^{[2]}$ Almost about 9\%$30 \%$ of the reproductive age group women have menstrual irregularities that requires medical evaluation. ${ }^{[3]}$ This proportion rises to around $70 \%$ in peri and postmenopausal women. Abnormal uterine bleeding can be due to structural cause or non-structural causes. ${ }^{[4]}$ In premenopausal woman, AUB is diagnosed when there is change in frequency, duration or amount of bleeding during 
or between periods. In post-menopausal, any vaginal bleeding 1 year after cessation of menses is considered abnormal. The major concern are endometrial hyperplasia and carcinoma-. The international federation of gynaecology and obstetrics (FIGO) classification system for the cause of AUB in non-gravid women of reproductive age (PALM-COEIN) P-polyp, Aadenomyosis, L-leiomyoma,

M-malignancy, C-coagulopathy, O-ovulatory disorder, E-endometrial cause, I-iatrogenic, Nnon- classified. ${ }^{[1]}$ The main aim of investigation of AUB is to rule out intra-uterine pathology, particularly endometrial cancer. ${ }^{[5]}$

Though hysteroscopy-directed endometrial biopsy is considered as gold standard for endometrial sampling, it carries the risk of

- General Anaesthesia

- Infection

- Perforation.

Concern regarding endometrial biopsy by aspiration are

- Adequacy of sample obtained

- Non sampling of focal intrauterine lesion

- Accuracy of histopathology report of tissue sampled. ${ }^{[6,7]}$

Dilatation and Curettage (D and C) under general anaesthesia has long been the gold standard for the assessment of AUB. The need for hospital admission, general anaesthesia, and the cost has made it less favourable. ${ }^{[4]}$ Recently, office procedures which are quick, safe, and inexpensive such as pipelle biopsy device, Vabra and $\mathrm{Z}$ sampler have superseded this technique with good patient acceptability. ${ }^{[5]}$ Pipelle is a flexible polypropylene device which works using a suction mechanism. It an ideal outpatient endometrial biopsy procedure. Endometrial aspiration using pipelle is a well-tolerated procedure and thus obviates the requirement for ward admission, operating theatre time and anaesthesia. On the other hand, endometrial aspiration using pipelle is simpler and comfortable for patients. It does not require general anaesthesia. It is also safe, cost effective, accurate and an outpatient procedure. It also enables quick sampling and the entire procedure can be completed in 10-15 minutes

There are very few studies that have analysed the efficacy of pipelle biopsy or validated this method of endometrial sampling against the gold standard histopathological diagnosis from hysterectomy specimens. Hence this study was conducted at dept of obstetrics and gynaecology, IMS and SUM Hospital, Bhubaneshwar to analyze the role of Pipelle's endometrial sampling and its accuracy in the assessment of endometrial pathology and its validity has been compared to hysteroscopyguided biopsy

\section{Aim}

- To find out a simple effective and alternate procedure to hysteroscopy guided endometrial biopsy.

\section{Objectives}

- To find out the efficacy of endometrial cytology in detecting different normal and abnormal endometrial patterns.

- Compare the efficacy of endometrial cytology with hysteroscopy guided biopsy.

\section{Material and Method}

1) Study Design: Prospective comparative study.

2) Study Setting: Patient aged 35 years and above with abnormal uterine bleeding attending OPD of dept of OBGY, IMS and SUM Hospital, Bhubaneshwar.

3) Study Duration: 1 year 6 months

4) Sample Size: 100 PATIENTS. The sample size may vary during the study.

\section{5) Study Population:}

Normal menstruation is defined as:

\begin{tabular}{|l|c|}
\hline Cycle interval & 28days \\
\hline Menstrual flow & 4-5days \\
\hline Amount of blood loss & $35 \mathrm{ml}(20-80 \mathrm{ml})$ \\
\hline
\end{tabular}

- Any patient with bleeding outside the normal value will be stamped as having abnormal uterine bleeding. 
6) Data Collection Procedure: After taking an informed consent process, the patient with abnormal uterine bleeding were included in the study. After taking proper history, all patients were subjected to routine investigation including CBC, FBS, TSH, viral screening as per hospital protocol. All cases will be evaluated with pelvic ultrasound to rule out any intra uterine space occupying lesion of organic pathology. Endometrial thickness will be assessed simultaneously.

- Endometrial Cytology: With all aseptic measures endometrial aspirate collected from the uterine cavity by aspiration cannula as an outpatient procedure. 2 slides used for drawing thin uniform smear and fixed by acetone alcohol solution. Rest of the aspirate will be preserved in a container of normal saline for cell block preparation.

\section{Endometrial Biopsy: After 24-hour} hysteroscopy guided endometrial biopsy were taken using hysteroscopic punch biopsy forceps under total intravenous anesthesia in minor operation theatre. The samples were preserved in $10 \%$ formalin saline.

- Both the sample were analyzed by pathologist. saline preserved sample and alcohol fixed slides will be used for cytology whereas formalin preserved samples were used for histopathological analysis

- At the end, both the procedure was compared for statistical significance.

\section{7) Inclusion Criteria}

a) Women with symptom suggestive of AUB.

b) Women who are clinically stable and fit for hysteroscopy.

\section{8) Exclusion Criteria}

a) Pregnant woman

b) Women ongoing hormonal treatment

c) Lower genital tract infection

d) Pelvic inflammatory disease

e) Coagulation disorder

f) Nulliparous women

g) women with genital malignancy with therapy.

\section{Observations and Results}

This Prospective comparative hospital-based study was done in ninety-eight patients with abnormal uterine bleeding following the inclusion and exclusion criterion. Endometrial thickness was assessed and all cases with $<5 \mathrm{~mm}$ thickness will be excluded from the study.

Table 1: Mean age of the patients with Abnormal Uterine Bleeding

\begin{tabular}{|l|c|c|c||c||c|}
\hline \multirow{2}{*}{ Mean Age } & $\mathrm{N}$ & Minimum & Maximum & Mean & Std. Deviation \\
\cline { 2 - 6 } & 80 & 30 & 66 & 43.89 & 7.288 \\
\hline
\end{tabular}

Mean age of the patients was found 43.89 years and standard deviation was found 7.38 years.

Table 2: Age wise frequency distribution

\begin{tabular}{|l||c||c|}
\hline Age Group (in completed years) & Frequency & Percent \\
\hline \hline $\mathbf{3 0 - 3 9}$ & 26 & 32.5 \\
\hline \hline $\mathbf{4 0 - 4 9}$ & 35 & 43.8 \\
\hline \hline $\mathbf{5 0 - 5 9}$ & 17 & 21.2 \\
\hline $\mathbf{6 0 - 6 9}$ & 2 & 2.5 \\
\hline Total & 80 & 100.0 \\
\hline
\end{tabular}

Majority of the patients with Abnormal Uterine Bleeding i.e. 35(43.8\%) were found in the age group of 40 to 49 years followed by $26(32.5 \%)$ patients in the age group of 30 to 39 followed by
$17(21.2 \%)$ patients in the age group of 50 to 59 years of age. Only two $(2.5 \%)$ patients were found in the age group of 60 to 69 years. 
Table No: 3: Comparison between cytology and histopathology

\begin{tabular}{|l||c||c|}
\hline TYPES OF ENDOMETRIUM & CYTOLOGY & HISTOPATHOLOGY \\
\hline Secretory Endometrium & 15 & 15 \\
\hline Proliferative Endometrium & 6 & 6 \\
\hline Haemorrhagic Endometrium & 16 & 12 \\
\hline Hormonal Effect On Endometrium & 2 & 2 \\
\hline Non-Secretory Endometrium & 18 & 18 \\
\hline \hline Atrophic & 4 & 4 \\
\hline Hyperplasia Without Atypia (simple hyperplasia) & 9 & 13 \\
\hline Hyperplasia with Atypia & 5 & 5 \\
\hline \hline Cystic Hyperplasia & 5 & 5 \\
\hline \hline Total & 80 & 80 \\
\hline
\end{tabular}

In this study there was discrepancy between cytology and histology particularly in endometrial hyperplasia without atypia (simple hyperplasia), diagnosed in 9 cases in cytology whereas 13 cases (4 cases extra) were diagnosed in histopathology. Considering histopathology as gold standard, the four cases showing non co-relation in cytology were diagnosed as bleeding endometrium instead of Endometrial hyperplasia without atypia in histology. This is possibly due to inadequate cellularity in a haemorrhagic background in cytology. Other cases of cytology were well corelated with histological diagnosis.

Table 5: Sensitivity, Specificity, NPV, PPV and Accuracy of Cytopathology over Histopathology

\begin{tabular}{|l||c|c|}
\hline Statistic & Value & 95\% CI \\
\hline \hline Sensitivity & $100.00 \%$ & $93.62 \%$ to $100.00 \%$ \\
\hline \hline Specificity & $83.33 \%$ & $62.62 \%$ to $95.26 \%$ \\
\hline \hline Positive Predictive Value & $93.33 \%$ & $85.13 \%$ to $97.16 \%$ \\
\hline \hline Accuracy & $95.00 \%$ & $87.69 \%$ to $98.62 \%$ \\
\hline
\end{tabular}

The sensitivity, specificity, positive predictive value, negative predictive value and accuracy of cytology over gold standard histopathological confirmation is $100.00 \%, 83.33 \%, 93.33 \%, 100 \%$ and $95 \%$ respectively.

\section{Discussion}

Abnormal uterine bleeding (AUB) is a common reason for woman of all ages to consult their gynecologists. One-third of patients attending the Gynecology OPD present with complaints of AUB. ${ }^{[1]}$ This proportion rises to $70 \%$ in the perimenopausal and postmenopausal age group. ${ }^{[2]}$ The main aim of investigation for AUB is to rule out intrauterine pathology, particularly endometrial malignancy. ${ }^{[4]}$ In the present study, the incidence of AUB was maximum in the age group of 40-49 years followed by 30-39 years. Similar finding was observed by Moradanetal. ${ }^{[9]}$ Chandrakumari et al. ${ }^{[10]}$ and Kumari et al. ${ }^{[1]}$ Thus, highlighting that $\mathrm{AUB}$ is common during perimenopausal period. Critchley $\mathrm{HO}$ et $\mathrm{al}^{[12]}$ in UK also proved that Pipelle biopsy could obtain adequate endometrial sample in low-risk women of perimenopausal age (79\%) compared to highrisk postmenopausal women (43\%) Guido et al did Pipelle biopsies in 65 patients and found that adequate tissue for analysis was obtained in 97\% cases $^{[14]}$. Ben Baruch et al in Israel at the same time proved that sufficient endometrial sample was obtained in $90.6 \%$ of women and the discomfort caused was only very slight ${ }^{[13]}$. Guido and associates concluded that Pipelle is excellent for detecting global processes of the endometrium 
than focal lesions ${ }^{[14]}$. The results were similar in our study where Pipelle missed focal lesions, i.e. 4 of 5 polyps detected by hysteroscopy and a case of submucous fibroid that was missed by Pipelle was diagnosed by hysteroscopy. Endometrial cytology is inexpensive, tolerated well and can be performed without anaesthesia in an outpatient clinic. It is now the most common test for an initial evaluation of endometrial cancer in $\operatorname{Japan}^{[21]}$ and has been encouraged as the first level screening method for women at high risk for endometrial cancer ${ }^{[22]}$.

On HPE, in the present study, normal type of endometrium was observed in 50\% of the patients, and hyperplastic endometrium in $22.5 \%$ cases which is less than that reported by Supriya et al. $(38 \%),{ }^{[20]}$ and atrophic endometrium was noted in $15 \%$ cases. However, higher incidence was observed by Rachamallu et al. and they reported simple hyperplasia without atypia in $57.1 \%$ and $61 \%$ cases by Pipelle and D\&C method, respectively. ${ }^{[3]}$ In the present study there was discrepancy between cytology and histology, abnormal histopathological findings particularly endometrial hyperplasia was reported in 4 extra cases. The four cases showing non-co-relation in cytology were diagnosed as bleeding endometrium instead of endometrial hyperplasia without atypia in histopathology. This is possibly due to inadequate cellularity in hemorrhagic background in cytology. This can be prevented by increasing expertise of the sample collector. There was sensitivity in detecting simple hyperplasia $(12.5 \%)$ and secretory $(17.5 \%)$ type of endometrium. While $25 \%$ cases of AUB were cytologically abnormal. Among these, secretory and hemorrhagic endometrium is detected among $13.5 \%$ cases and non-secretory among (22.5\%) and simple hyperplasia in $(11.2 \%)$ cases. We found statistical significance in difference while comparing cytological and histopathological endometrial findings. In our study, among five $(6.2 \%)$ cases as per cytology and five $(6.2 \%)$ case as per histopathology, malignancy i.e. hyperplasia with atypia was diagnosed. This is lower as compared to other studies ${ }^{[23,24]}$. The difference might be due to low incidence of endometrial malignancy in India as compared to western countries. Pipelle cytopathology had sensitivity, specificity, Positive predictive value and accuracy of cytology in comparison to gold standard histopathological confirmation is $100 \%, 83.3 \%$, $93.3 \%$, and $95 \%$ respectively. However, in study by Nalina et al., the sensitivity, specificity, PPV, and NPV of Pipelle biopsy in histologically detecting Endometrial abnormalities was 93\%, $90 \%, 88 \%$, and $94 \%$, respectively. ${ }^{[13]}$ Good accuracy of Pipelle biopsy, in the present study, was observed in detecting simple hyperplasia $(95 \%)$. Similar findings were demonstrated by various studies. ${ }^{[10,15,17-19]}$

\section{Conclusion}

Endometrial sampling using Pipelle is an easy and safe method for obtaining endometrial tissue for diagnosis in patients with abnormal uterine bleeding. It is minimally invasive OPD procedure and results in good results and accuracy due to its high sensitivity, specificity, positive and negative predictive values. It is cost-effective, cuts down the duration of hospital stay and results in high patient compliance in addition to the added advantage of no use of anesthesia or other procedure complications like perforation compared to hysteroscopy. Thus, to obtain adequate endometrial sample for HPE, in peri- and post-menopausal women with AUB and in resource poor centre, Pipelle biopsy should be considered as primary investigation.

\section{Bibliography}

1. Munro MG, Critchley HO, Broder MS, Fraser IS; FIGO Working Group on Menstrual Disorders. FIGO classification system (PALM-COEIN) for causes of abnormal uterine bleeding in nongravid women of reproductive age. Int $\mathbf{J}$ GynaecolObstet2011;113:3-13.

2. Tavassoli FA, Devilee pathology and genetics of tumours of breast and female 
genital organs. WHO classifications of tumors. Lyon,France:IARC press 2003:221-232.

3. Yasmin F, Farrukh R, Kamal F. Efficacy of pipelle as a tool for endometrial biopsy. Biomedica 2007; 23:116-9.

4. Rosai J. Female reproductive systemuterus-corpus. In: RosaiJ,ed.Rosai and Ackerman's surgical pathology. $9^{\text {th }}$ edn. vol.2. New delhi: Elsevier 2004:P 15691635.

5. Shams G. Comparison of pipelle de cornier with conventional dilatation and curettage in terms of patients' acceptability. J Postgrad Med Inst (Peshawar-Pakistan) 2012;26:418-21.

6. Rodriguez GC, Yaqub N, King ME. A comparison of the pipelle device and vibra aspirator as measured by endometrial denudation in hysterectomy specimens. Am J Obstet Gynecol 1993;168(1 pt 1):5559.

7. Guido RS, Kanbour-shakir A, Rulin MC et al. Pipelle endometrial sampling sensitivity in the detection of endometrial cancer. $\mathrm{J}$ Repord Med 1995;40(8):553-555.

8. The American Cancer Society Medical and Editorial Content Team. (2016). Survival rates for ovarian cancer, by stage.

9. cancer.org/cancer/ovariancancer/detection-diagnosisstaging/survival-rates.html

10. Goh W, Bohrer J, Zalud I. Management of the adnexal mass in pregnancy. Curr Opin Obstet Gynecol. 2014;26(2):49-53.

11. Stoval TG, Ling FW, Morgan PL. A prospective, randomized comparison of the pipelle endometrial sampling device with the novak curette. Am J Obstet Gynecol.1991;165:1287-90.

12. Altman D, Granath F, Cnattingius S, Falconer C. Hysterectomy and risk for stress-urinary-incontinence surgery: nationwide cohort study. Lancet, 2007; 370, 1494-1499.
13. Ben-Baruch G, Seidman DS, Schiff E, Moran O, Menczer J. Outpatient endometrial sampling with the Pipelle curette. Gynecol Obstet Invest. 1994;37(4):260-2.

14. Guido RS, Kanbour-shakir A, Rulin MC. et al. Pipelle endometrial sampling sensitivity in the detection of endometrial cancer. J Reprod Med 1995;40(8):553-555.

15. Van den Bosch T, Vandendael A, Wranz PA, Lombard CJ. Endopap-versus Pipellesampling in the diagnosis of postmenopausal endometrial disease. Eur J Obstet Gynecol Reprod Biol. 1996;64 (1):91-4.

16. Bunyavejchevin S, Triratanachat S, Kankeow K, Limpaphayom KK. Pipelle versus fractional curettage for the endometrial sampling in postmenopausal women. J Med Assoc Thai. 2001;84 Suppl 1:S326-30.

17. 15. Bain C, Parkin DE, Cooper KG. Is outpatient diagnostic hysteroscopy more useful than endometrial biopsy alone for the investigation of abnormal uterine bleeding in unselected premenopausal women? A randomised comparison. BJOG. 2002;109(7):805-11.

18. Dangal G. A study of endometrium of patients with abnormal uterine bleeding at Chitwan Valley. Kathmandu Univ Med J (KUMJ). 2003;1(2):110-2.

19. Tanriverdi HA, Barut A, Gün BD, Kaya E. Is pipelle biopsy really adequate for diagnosing endometrial disease? Med Sci Monit. 2004 Jun;10(6):CR271-4.

20. Garuti G, Sambruni I, Colonnelli M, Luerti M. Accuracy of hysteroscopy in predicting histopathology of endometrium in 1500 women. J Am Assoc Gynecol Laparosc. 2001;8(2):207-13.

21. Fujiwara H, Takahashi Y, Takano M, Miyamoto M, Nakamura K, Kaneta Y, et al. Evaluation of endometrial cytology: cytohistological correlations in 1,441 
cancer patients. Oncology. (2015) 88:8694.

22. Fulciniti F, Yanoh $K$, Karakitsos $P$, Watanabe J, Di LA, Margari N, et al. The Yokohama system for reporting directly sampled endometrial cytology: the quest to develop a standardized terminology. Diagnost Cytopathol. (2018) 46:400-12.

23. Tingthanatikul Y, Choktanasiri W, Rochanawutanon M, Weerakeit S. Prevalence and clinical predictors of endometrial hyperplasiain anovulatory women presenting with amenorrhea. Gynecol Endocrinol 2006;22:101-5.

24. Timmermans A, Opmeer BC, Khan KS, Bachmann LM, Epstein E, Clark TJ, et al. Endometrial thickness measurement for detecting endometrial cancer in women with postmenopausal bleeding: A systematic review and meta-analysis. Obstet Gynecol2010;116:160-7. 